\title{
An airborne perfluorocarbon tracer system and its first application for a Lagrangian experiment
}

\author{
Y. Ren, R. Baumann, and H. Schlager \\ Deutsches Zentrum für Luft- und Raumfahrt (DLR), Institut für Physik der Atmosphäre, Oberpfaffenhofen, Germany \\ Correspondence to: Y. Ren (yu.ren@dlr.de)
}

Received: 9 June 2014 - Published in Atmos. Meas. Tech. Discuss.: 10 July 2014

Revised: 18 November 2014 - Accepted: 28 November 2014 - Published: 9 January 2015

\begin{abstract}
A perfluorocarbon tracer system (PERTRAS), specifically designed for Lagrangian aircraft experiments, has been developed by the Deutsches Zentrum für Luft- und Raumfahrt (German Aerospace Center, DLR). It consists of three main parts: a tracer release unit (RU), an adsorption tube sampler (ATS), and a tracer analytical system. The RU was designed for airborne tracer release experiments; meanwhile, it can be used on various platforms for different experimental purposes (here research vessel). PERTRAS was for the first time applied in the field campaign Stratospheric ozone: Halogen Impacts in a Varying Atmosphere (SHIVA) in November 2011. An amount of $8.8 \mathrm{~kg}$ perfluoromethylcyclopentane (PMCP) was released aboard the research vessel Sonne (RV Sonne) near the operational site of this campaign, Miri, Malaysia, on 21 November. The tracer samples collected using the ATS onboard the DLR research aircraft Falcon were analyzed in the laboratory using a thermal desorber-gas chromatography-mass spectrometry (TDGC-MS) system. Guided by forecasts calculated with the Lagrangian model Hybrid Single Particle Lagrangian Integrated Trajectory (HYSPLIT), 64 tracer samples were collected onboard the Falcon approximately 5 and $25 \mathrm{~h}$ after the release, mostly with a time resolution of $1 \mathrm{~min}$. Enhanced PMCP concentrations relative to ambient PMCP background values (mean: $6.62 \mathrm{fmol} \mathrm{mol}^{-1}$ ) were detected during three intersects of the fresh tracer plume (age $5 \mathrm{~h}$ ), with a maximum value of $301.33 \mathrm{fmol} \mathrm{mol}^{-1}$. This indicates that the fresh tracer plume was successfully intercepted at the forecast position. During the second flight, $25 \mathrm{~h}$ after the release, the center of tracer plume was not detected by the sampling system due to a faster advection of the plume than forecast. The newly developed PERTRAS system has been successfully deployed for the first time. The instrumental setup and
\end{abstract}

comparisons between the measurements and HYSPLIT simulations are presented in this study.

\section{Introduction}

Lagrangian experiments are a powerful tool in atmospheric investigations of the evolution of aerosols, clouds, and reactive chemical species during transport (Huebert and Lenschow, 1999). The approach in Lagrangian experiments is to measure the change of the composition of a single air mass as it moves using successive aircraft flights. A number of successful airborne Lagrangian experiments in the free troposphere have been performed using ambient tracers, including ASTEX/MAGE (Clarke et al., 1996), ACE-1 (Bates et al., 1998), COBRA (Lin et al., 2004), and ICARTT (Fehsenfeld et al., 2006; Methven et al., 2006). However, it was recognized during these experiments that the ability to quantify the microphysical and chemical processes during transport could be greatly enhanced with the use of an artificial tracer for non-ambiguous air mass identification and information on mixing processes.

Perfluoroalkylcycloalkanes (hereafter PFCs) are regarded as ideal tracer compounds for the investigation of atmospheric transport and dispersion because they are non-toxic, non-reactive, non-scavenging, and non-depositing, and they contribute neither to stratospheric ozone depletion nor to tropospheric air pollution. Furthermore, PFCs have also been used for many other applications, including detection of fluid leaks in underground pipes, testing of effectiveness of underground storage tanks and covered waste sites, and determination of indoor air exchange rates. Furthermore, PFCs have a 
limited industrial use and thus have a low atmospheric background concentration, which is important for long-range Lagrangian experiments. The observed background concentrations of most PFCs used are at mixing ratios of typically a few parts per $10^{15}\left(\mathrm{fmol} \mathrm{mol}^{-1}\right)$ (Piringer et al., 1997; Straume et al., 1998; Kim et al., 2002; Simmonds et al., 2002; Watson et al., 2007). They are potent greenhouse gases with a high global warming potential (GWP of about 7000). However, due to the very small atmospheric burden their global warming impact is insignificant compared to other greenhouse gases (Watson et al., 2007). Watson et al. (2007) estimated that the present total PFC radiative forcing (RF) is approximately $2 \times 10^{-5} \mathrm{~W} \mathrm{~m}^{-2}$. A PFC release into the atmosphere of $10 \mathrm{~kg}$ during a tracer experiment represents a negligible greenhouse contribution $\left(\sim 5 \times 10^{-11} \mathrm{~W} \mathrm{~m}^{-2}\right)$ compared to the combined anthropogenic $\mathrm{RF}\left(1.6 \mathrm{~W} \mathrm{~m}^{-2}\right)$ estimated by the 2007 IPCC (International Panel on Climate Change) Fourth Assessment Report.

PFCs can be detected down to background concentrations by enrichment on a solid adsorbent, separation by gas chromatography (GC), and detection using electron capture detection (ECD) (DeBortoli and Pecchio, 1985; Dietz, 1986; Lagomarsino, 1996; Straume et al., 1998). In recent years, due to the excellent selectivity and sensitivity and simple manipulation process, the analytical method with negative ion chemical ionization mass spectrometry (NICI-MS) for PFCs has increasingly been used (Begley et al., 1988; Galdiga and Greibrokk, 2000; Cooke et al., 2001; Simmonds et al., 2002).

The major PFC tracers - such as PMCP, perfluoromethylcyclohexane (PMCH), and perfluorodimethylcyclohexanes (PDCHs) - are liquids with the appreciable vapor pressure and relatively low boiling point at atmospheric temperature and pressure. They can be released into the atmosphere by either atomization or vaporization followed by dilution to prevent condensation until the vapors are sufficiently diluted below the ambient dew point concentration (Dietz, 1986). In previous experiments, the PFCs were released by being directly introduced into the fast-moving air stream (Ferber et al., 1981) or through the evaporation after increasing the temperature above the tracers' boiling point with a heater (Draxler, 1985; Draxler et al., 1991). Afterwards, adsorbent samplers, as the most popular established technique for sampling PFCs, were used to collect the tracer gas in the air (Ferber et al., 1981; Dietz, 1986; Draxler et al., 1991). So far, mainly ground-based tracer experiments using PFCs have been performed in North America and Europe at continental and regional scales (Ferber et al., 1986; Draxler and Heffter, 1989; Ambrosetti et al., 1998; Nodop et al., 1998; Green, 1999; Johnson et al., 2000; Green et al., 2003). During these experiments the PFCs have been released from ground sites and ships and subsequently measured at different ground stations. Although airborne measurements (Ferber et al., 1986; Ambrosetti et al., 1998; Nodop et al., 1998; Johnson et al., 2000; Green et al., 2003) have also been conducted for studies of the vertical mixing and dispersion of PFC-tagged air mass in some campaigns, these experiments were focused on the tracer transport near the ground. So far, no PFC tracer release and sampling system suitable for a deployment onboard research aircraft in the free troposphere (FT) and the upper troposphere-lower stratosphere (UT-LS) have been reported.

In this paper, we present a new perfluorocarbon tracer system, PERTRAS, which was developed especially for airborne tracer release and detection. Two newly constructed automatic modules are parts of the system: a PFC release unit (RU) and an adsorption tube sampler (ATS). Combined with the well-established analytical technique of thermal desorber (TD)-GC-NICI-MS, the PERTRAS system was applied for the first time in the field campaign SHIVA. Section 2 gives a detailed description of the system. The tracer experiment during SHIVA is described in Sect. 3. In Sect. 4, the results of the first of the PERTRAS applications are presented. Finally, a summary and conclusion are given in Sect. 5.

\section{Instrumental setup}

A very first prototype of an airborne PFC release and sampling system was built in cooperation with the Brookhaven National Laboratory and used for a pilot tracer experiment. However, leakage problems and aircraft certification issue required the construction of new RU and ATS modules, specifically designed for airborne operation. Here, stainless-steel adsorption tubes used for the sampler are completely compatible with most commercially available thermal desorber systems. In the next subsections, the instrumental setup of the PFC RU and ATS and the post analysis process in the laboratory are described in more detail.

\subsection{PFC release unit (RU)}

The basic principle of the PFC RU is to release the tracer liquid by spraying aerosol into a gas flow in the atmosphere through the process of high-pressure atomization using a spray nozzle. Figure 1 shows a schematic diagram of the design of the PFC RU (left) and the aircraft module (right). It consists of three $6.6 \mathrm{~L}(\sim 10 \mathrm{~kg}$ liquid PFCs each) stainlesssteel tanks. Depending on the planned experiments, up to $30 \mathrm{~kg}$ in total and three different PFCs can be released. The release rate can be set between 0.1 and $500 \mathrm{~mL} \mathrm{~min}^{-1}$ with an uncertainty of $2 \%$ using a high-pressure liquid chromatography (HPLC) pump (Knauer, Germany, type 1800). The pressure in the tube to the PFC outlet is adjustable between 40 and 100 bar. A $500 \mathrm{~mL}$ stainless-steel cylinder of nitrogen (grade 5.0, Praxair) is installed ahead of the PFC tanks, and during release nitrogen is used for equalization of the pressure in the tanks. The operation of the RU is achieved by using an onboard PC running LabVIEW through a touch screen control panel, or by remote controlling from a laptop through virtual network computing (VNC). The different PFC tanks can be selected by switching a three-way valve through con- 

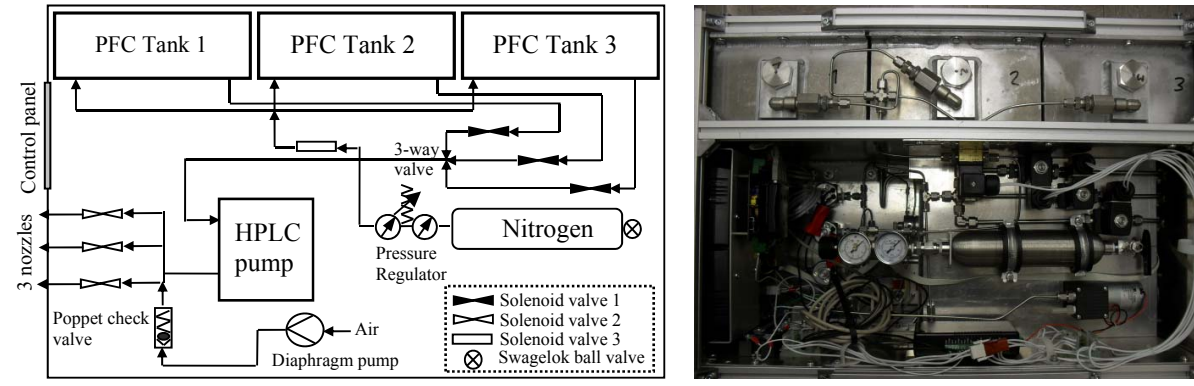

Figure 1. PFC release unit: schematic of gas flow (left); aircraft release module (right).

trolling the solenoid valves (Fig. 1 (left), solenoid valve 1). Then the release can start automatically by pressing the button on the controlling panel after a release program is set up. Three spray nozzles are used to disperse PFC droplets with diameters less than $20 \mu \mathrm{m}$ into the fast-moving airstream. They are selected by controlling the solenoid valves (Fig. 1 (left), solenoid valve 2), which are connected to the outlet tube of the HPLC pump. The HPLC pump maintains the pressure necessary for the nozzles to operate in the range where the droplets will be within this size range needed to avoid sedimentation of the droplets before evaporation. The RU has a total weight of $47 \mathrm{~kg}$.

During the release operation, the small PFC droplets are dispersed into the wake of the aircraft or ship or the air flow at ground level. When the release is performed aboard an aircraft, the RU is installed in a rack in the aircraft cabin and the PFC release is through a special outlet mounted into the fuselage. For security reason, an additional container is integrated in the rack capable of housing the total amount of PFCs in case of a leak during flight. The PFC RU can both be used for ground-based and ship-based releases as well, depending on the different objectives of the experiments. During SHIVA the latter release platform was chosen, and the PFC RU $(65.0 \mathrm{~cm} \times 48.5 \mathrm{~cm} \times 35.5 \mathrm{~cm})$, shown in Fig. 1 (right), was installed on the deck of the stern of the research vessel (RV) Sonne. The sprayer was fixed at the pillar of the gunwale about $10 \mathrm{~m}$ above the sea surface.

\subsection{Aircraft adsorption tube sampler (ATS)}

The components of the aircraft ATS are shown schematically in Fig. 2. This sampler was constructed specifically for the purpose of airborne sampling. It consists of four 16-position multiport valves (Valco Instruments Co. Inc.). The sampler can collect a maximum of 64 samples with the standard adsorption tubes (outer diameter: $6.35 \mathrm{~mm}$; inner diameter: $5 \mathrm{~mm}$; length: $89 \mathrm{~mm}$; material: stainless steel) continuously or selectively according to the experimental requirements. The four multiport valves are incorporated into a modified metal bellow pump (Ansyco, Germany). The flow rate is controlled by a metal mass flow controller (MFC, Bronkhorst, USA). The selection of the sampling tube is operated by the

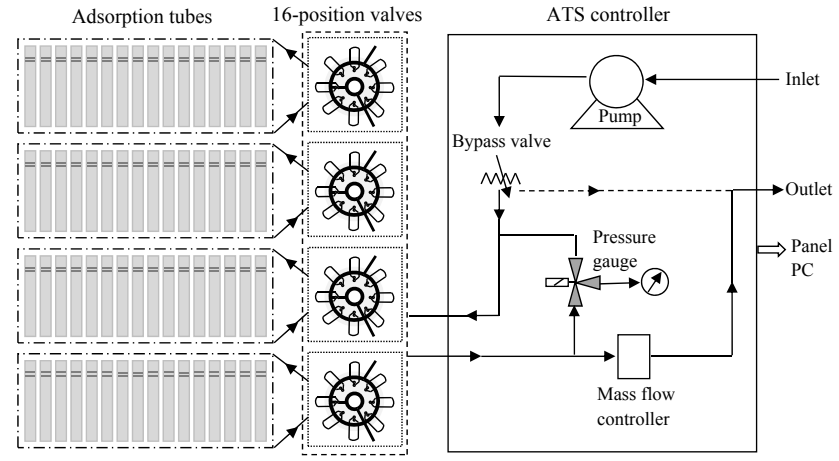

Figure 2. Schematic of the ATS. In standby or waiting mode, gas flow occurs through the dashed lines to the outlet. In sampling mode, gas flow is through the solid lines into the adsorption tubes.

touch screen of an integrated aircraft ATS controller. Depending on different experimental purposes, the sampling flow, sampling time and the interval between two samples, etc., can be controlled through the touch screen as well. After a sampling sequence is programmed, the system runs automatically.

The gas flow has two different modes: standby/waiting and sampling. When the sampler is in the mode of standby (ready for sampling) or waiting for sampling (during the time intervals between two samples), ambient air is drawn into the system by the metal bellow pump (Fig. 2, through the dashed lines) directly without flowing through the adsorption tubes. When the ATS starts to sample, ambient air is drawn into selected adsorption tubes and the sampling flow is controlled by a MFC. Different amounts of sample air can pass through the tubes at optional intervals, and perfluorocarbon tracer molecules are trapped and concentrated in the tubes onto adsorbent material. The volume and the time of air passed through the tubes are recorded. After one sampling sequence is finished, the ATS is switched back to standby mode automatically. Before installing the ATS into an aircraft, the test of airtightness for each tube is conducted at the ground with high-purity, PFC-free nitrogen. During the field experiment SHIVA, the ATS $(53.0 \mathrm{~cm} \times 48.5 \mathrm{~cm} \times 16.0 \mathrm{~cm}$, $23.6 \mathrm{~kg}$ ) (Fig. 3) was installed in the DLR research aircraft 

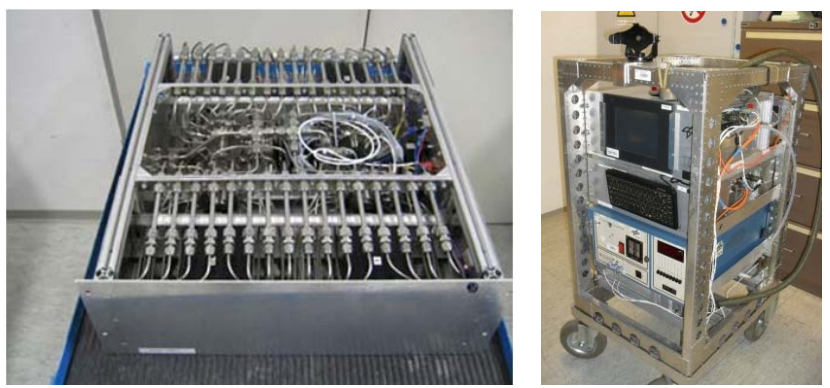

Figure 3. Adsorption tube setup in the sampler ATS (left) and aircraft instrument rack including PERTRAS and ozone and $\mathrm{CO}$ instruments (right).

Falcon. The inner part of the ATS module is depicted in Fig. 3 (left). Figure 3 (right) shows the ATS integrated in the aircraft rack together with ozone and $\mathrm{CO}$ instruments.

Stainless-steel adsorption tubes (PerkinElmer, USA) are used to collect PFCs, filled with about $200 \mathrm{mg}$ Carboxen 569 (20-45 mesh, Supelco, USA). After filling with Carboxen 569 , all sampling tubes are conditioned at $260^{\circ} \mathrm{C}$ for at least $5 \mathrm{~h}$ under a constant flow of high-purity helium (Alphagaz ${ }^{\mathrm{TM}}$ $\mathrm{He}, 6.0$, Air Liquide). The tubes are periodically checked by GC-MS to ensure that they are free of PFCs before sampling.

Using adsorption tubes for the collection of gas samples, the suitable sampling volume related to the breakthrough of the analytes on the adsorbent material needs to be considered. There are many different definitions of breakthrough volume (BTV). It is usually defined as the gas volume which passes through the adsorbent bed before a given compound begins to be eluted from the sorbent. Different sample volumes were tested to ensure that no PFC tracer had broken through the adsorbent bed during sampling. For this, the first blank adsorption tube of Carboxen 569 was loaded with a certain amount of gas PFC standard. This tube was connected in series with another blank tube to retain the PFCs eluted from the front to the back sorbent tube (Aragón et al., 2013). The results showed that there was no PFC penetration with $40 \mathrm{~L} \mathrm{PFC}$-free nitrogen at the flow rate of $200 \mathrm{~mL} \mathrm{~min}^{-1}$ flushing through the adsorption tubes at $20^{\circ} \mathrm{C}$. The theoretical BTV of these sample tubes with Carboxen 569 should be higher than $40 \mathrm{~L}$ for most PFCs. In addition, according to the results of Yang et al. (2005), the penetration volume of perfluorodimethylcyclobutane (PDCB) is almost independent of the flow rate $\left(\leq 1.5 \mathrm{~L} \mathrm{~min}^{-1}\right)$ of the mobile phase. Other PFCs have stronger adsorption ability than PDCB on Carboxen 569. Therefore, several liters of PFCs with less than $1.5 \mathrm{~L} \mathrm{~min}^{-1}$ flow rate can be trapped onto the sampling tube without exceeding the theoretical BTV.

\subsection{Analytical instruments}

The identification of the PFCs and quantification of their concentrations is accomplished offline by using an analyti- cal system consisting of a GC (TRACE GC Ultra) connected with a pre-concentrated thermal desorber and a mass spectrometer in the laboratory. Here only a brief description of the analytical process is given. More details are given by Ren et al. (2014). Thermal desorption was carried out with a thermal desorber ATD650 (PerkinElmer, USA). The ATD650 was connected to the injection port of the GC through a temperature-controlled interface. With a two-step desorption, the sample which has been enriched into the cold trap, maintained at a temperature of $-30^{\circ} \mathrm{C}$, can be desorbed in $\sim 3 \mathrm{~s}$ onto the analytical column in the GC (Tracer GC Ultra) oven in split mode. The cold trap was filled with about $100 \mathrm{mg}$ Carboxen 569 (20-45 mesh, Supelco, USA) and conditioned by heating at $260^{\circ} \mathrm{C}$ with carrier gas for at least $5 \mathrm{~h}$ under high-purity helium to clean prior to the normal analysis. The temperature of both the interface and the valve was set at $200^{\circ} \mathrm{C}$.

The separation of the tracer was carried out on a $30 \mathrm{~m} \times 0.25 \mathrm{~mm} \times 5.0 \mu \mathrm{m} \mathrm{Al}{ }_{2} \mathrm{O}_{3}$-PLOT-S capillary column (HP-PLOT $\mathrm{Al}_{2} \mathrm{O}_{3} \mathrm{~S}$, Agilent, USA). A particle trap $5 \mathrm{~m} \times 0.25 \mathrm{~mm}$ deactivated fused silica column (Agilent, USA) was connected to the $\mathrm{Al}_{2} \mathrm{O}_{3}$-PLOT-S to avoid particles shedding from the stationary phase layer of PLOT capillary column entering the MS detector. The following oven temperature program was set up: $100^{\circ} \mathrm{C}(0.5 \mathrm{~min})$, $30^{\circ} \mathrm{C} \mathrm{min}^{-1}$ to $130^{\circ} \mathrm{C}(6.5 \mathrm{~min}), 30^{\circ} \mathrm{C} \mathrm{min}^{-1}$ to $140^{\circ} \mathrm{C}$ (23 min), then $20^{\circ} \mathrm{C} \mathrm{min}^{-1}$ to $190^{\circ} \mathrm{C}(5 \mathrm{~min})$. High-quality helium (Alphagaz ${ }^{\mathrm{TM}} \mathrm{He}, 6.0$, Air Liquide) was used as carrier gas with a flow rate of $1 \mathrm{~mL} \mathrm{~min}{ }^{-1}$. The mass spectrometer was operated in negative ion chemical ionization (NICI) mode at $70 \mathrm{eV}$ and in selected ion monitoring (SIM) mode. Methane (N55 quality, Air Liquide) was used as reagent gas. The GC-MS interface and the source temperature were set to $190^{\circ} \mathrm{C}$. It has been demonstrated by Ren et al. (2014) that this detection system can be used for routine laboratory analysis of several PFCs with good sensitivity and selectivity including PMCP, PMCH, PDCH, PDCB, and PECH (perfluoroethylcyclohexane).

Samples were calibrated using a gas standard prepared at the University of Bristol (Simmonds et al., 2002). The limit of detection (LOD) of the method for PMCP was $1.2 \mathrm{ppq}\left(\mathrm{fmol} \mathrm{mol}^{-1}\right)$, detected with a 3 times signal-to-noise ratio. The precision of PMCP during the analytical process was $\pm 4.6 \%$. The calibration appeared to be linear at least 3 orders of magnitude for the concentrations that were studied.

\section{Field deployment of PERTRAS}

\subsection{SHIVA - measurement campaign}

SHIVA is a European Union (EU)-funded research project (http://shiva.iup.uni-heidelberg.de/) with the main objective of reducing uncertainties in present and future stratospheric halogen loading and ozone depletion. Of particular relevance 
are studies of short- and very short-lived substances (VSLS) with climate-sensitive natural emissions. A core field campaign was conducted during November-December 2011 in the tropical western Pacific region with measurements along the coastline of the Peninsular Malaysia and Borneo using ships and aircraft. The campaign base of the DLR research aircraft Falcon was Miri on Borneo, Malaysia. One measurement objective was to study the transport and dispersion of VSLS halocarbons produced from seaweed along the coast of Borneo in the marine boundary layer and the entrainment of these emissions in the FT (Aschmann et al., 2009; Tegtmeier et al., 2012, 2013). SHIVA provided the opportunity to deploy the PERTRAS system for the first time in the framework of a Lagrangian experiment. In the following, the experimental details of the tracer release and collection are given.

\subsection{Tracer release}

The PFC tracer release was conducted from the German RV Sonne. Therefore the release unit with PMCP was set up on the deck of RV Sonne. The time of the tracer release was selected based on HYSPLIT forecasts. An amount of $8.8 \mathrm{~kg}$ pure PMCP was released on 21 November 2011 from $02: 24 \mathrm{UTC}\left(112.96^{\circ} \mathrm{E}, 4.51^{\circ} \mathrm{N}\right)$ to $03: 03 \mathrm{UTC}\left(113.01^{\circ} \mathrm{E}\right.$, $\left.4.56^{\circ} \mathrm{N}\right)$. The release position along the Sonne route is depicted in Fig. 4 as site $\mathrm{C} 4$.

\subsection{HYSPLIT simulation and the flight patterns}

Version 4 of HYSPLIT (Draxler and Hess, 1997, 1998; http://www.arl.noaa.gov/ready/hysplit4.html) was employed to forecast and simulate the transport and dispersion of the PFC tracer and to support flight planning. Data from the Global Forecast System (GFS, for forecast) and Global Data Assimilation System (GDAS, for analysis) with $1^{\circ} \times 1^{\circ}$ horizontal resolution and $3 \mathrm{~h}$ time intervals were used as meteorological input for HYSPLIT. Data were given on pressure levels with a resolution of $25 \mathrm{hPa}$ within the lower atmosphere. HYSPLIT was operated in particle dispersion mode, and all parameterizations were set to the standard values. The release species was treated as a passive gas tracer without deposition. The simulation takes into account the movement of the ship during the release; that is, the release is split into 39 point sources (one for each minute) shifted in space and time according to the ship course. The HYSPLIT forecast was regularly updated every $6 \mathrm{~h}$ based on the latest available GFS data.

Figure 5 shows HYSPLIT forecasts of tracer concentrations after PMCP was released from the RV Sonne on 21 November 2011 over a dispersion period of 5 and $25 \mathrm{~h}$. The forecasted maximum concentration in the PMCP tracer plume is depicted in dark red. Based on these forecasts, the corresponding flight plan of the Falcon on these 2 days was made, and the flight tracks for the two flights are also illustrated in Fig. 5.

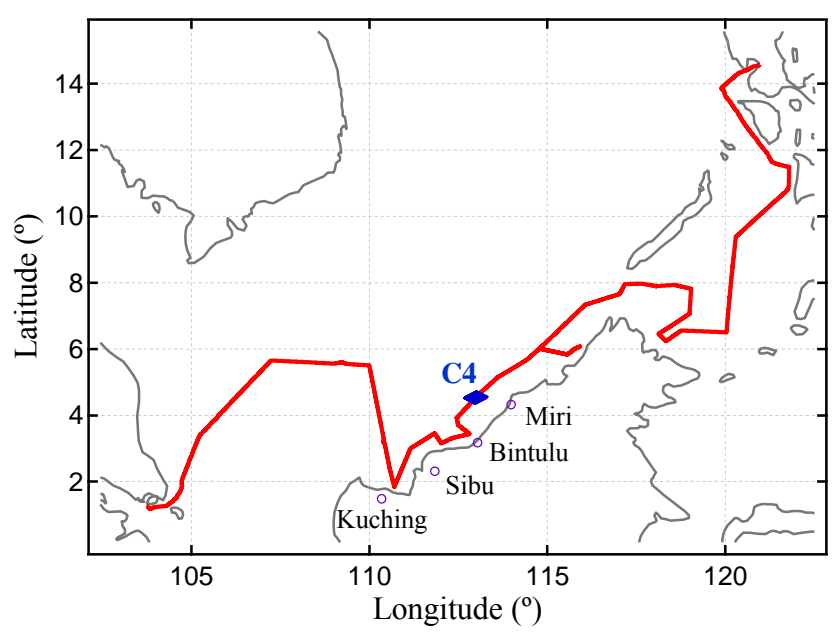

Figure 4. Route of the RV Sonne during SHIVA field campaign (red line) and the position (C4) of the tracer release: PMCP was released on the deck of Sonne from 02:24 to 03:03 UTC on 21 November 2011 .

\subsection{Tracer sampling}

The ATS was successfully deployed onboard the Falcon during two flights conducted on 21 and 22 November 2011. The aim was to test and verify the operation of the whole analytical system and to compare the tracer measurements with the HYSPLIT simulation. Therefore, multiple Falcon transects were planned through the center of the tracer plume based on the HYSPLIT forecasts, as shown in Fig. 5. In general, the collection of samples was started several minutes before the expected entering of the tracer plume according to the forecast, and sampling was terminated a few minutes after the expected exit of the plume. On 21 November, the Falcon performed two intersections of the plume rotated by $90^{\circ}$, at two altitudes (170 and $500 \mathrm{~m}$ ), about $75 \mathrm{~km}$ away from the release point. Before flying back to Miri, the aircraft ascended to about $1000 \mathrm{~m}$, trying to catch the highest plume part according to the vertical cross-section map. On 22 November, the Falcon flew through the elongated plume at about 800 and $1200 \mathrm{~m}$, about $150 \mathrm{~km}$ away from the release point. All samples were collected at $1 \mathrm{~L} \mathrm{~min}^{-1}$ for $1-1.5 \mathrm{~min}$. There were 0.5 to $2 \mathrm{~min}$ intervals between two samples in a sampling sequence, and the intervals were adjusted due to the actual sampling situation. During the sampling periods, the aircraft speed ranged from 101 to $112 \mathrm{~m} \mathrm{~s}^{-1}$ (21 November) and from 123 to $140 \mathrm{~m} \mathrm{~s}^{-1}$ (22 November); thus $1-1.5 \mathrm{~min}$ collection times result in a horizontal grid spacing of about 6-10 and 7-13 km, respectively. In accordance with the flight plan, in total 64 samples were obtained on these two flights, including four blanks for quality control to check whether any contamination of the sampling tubes had taken place during transport, sampling, or analysis. To avoid contamination, the sampling tubes had been separated strictly from the tracer 

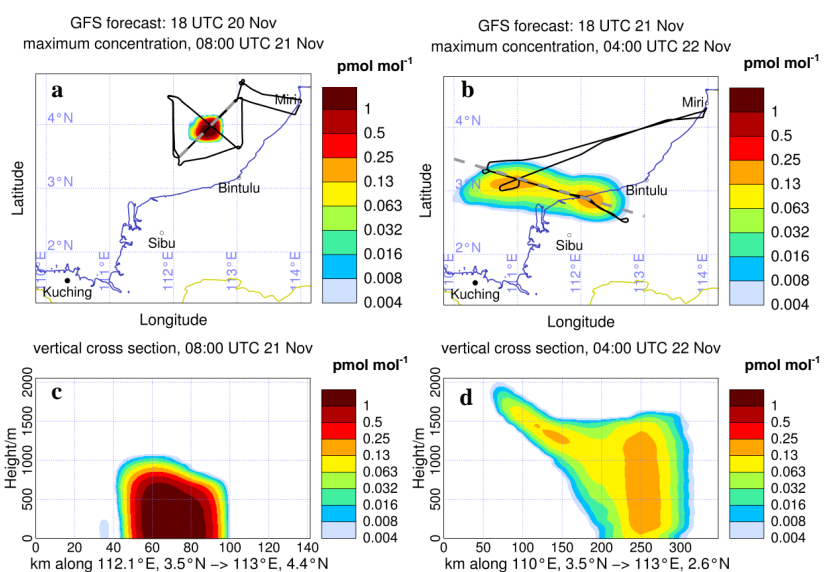

Figure 5. HYSPLIT forecasts of the horizontal and vertical distribution of the PFC concentration at the northern coast of Borneo, $5 \mathrm{~h}$ (a and c) and $25 \mathrm{~h} \mathrm{(b}$ and $\mathbf{d}$ ) after the release of the tracer. The flight tracks of the two Falcon sampling flights are also shown (black lines in $\mathbf{a}$ and $\mathbf{b}$ ). The thick dashed lines (grey) indicate the location of vertical cross sections (c and $\mathbf{d}$ ).

storage tank and the tracer releaser system during the whole campaign.

In addition, a commercial sequential tube sampler (STS 25, PerkinElmer, USA) was used to collect background samples at a rural site $\left(112.978^{\circ} \mathrm{E}, 4.398^{\circ} \mathrm{N}\right)$ near the airport of Miri, about $9 \mathrm{~km}$ south of the center of Miri. Using a sampling flow rate of $200 \mathrm{~mL} \mathrm{~min}^{-1}$, air samples were trapped onto adsorption tubes for $40 \mathrm{~min}$. A total of 37 samples were collected between 20 November and 5 December 2011, including 8 blanks, which were also used for quality control purposes. Since the plume of the released PMCP tracer was not advected to Miri, background samples could still be collected at the ground in Miri after the release experiment. Before and after the ground-based sampling, the flow through every sampling orifice of the ground sampler was measured with a Gillian Galibrator-2 (Scientific Instrument Services, Inc ${ }^{\mathrm{TM}}$, USA). After the sampling period, the tubes were sealed immediately at both ends with $1 / 4 \mathrm{in}$. brass storage caps with $1 / 4 \mathrm{in}$. PTFE ferrules and stored until analysis.

\section{Results and discussion}

The analysis of all blank tubes showed that no contamination occurred during the transport of the tubes to and from the campaign site, nor during sampling, storage, or analysis. The measured background concentrations of PMCP at the ground near Miri range between 5.18 and $8.95 \mathrm{fmol} \mathrm{mol}^{-1}$, with a mean value of $6.62 \mathrm{fmol} \mathrm{mol}^{-1}$ and a standard deviation of $1.02 \mathrm{fmol} \mathrm{mol}^{-1}\left(6.62 \pm 1.02 \mathrm{fmol} \mathrm{mol}^{-1}\right)$. This is comparable to PMCP levels reported from previous field experiments (Kim et al., 2002; Simmonds et al., 2002; Watson et al., 2007; Ren et al., 2014). In the following subsections, the analytical results of the tracer measurements with PERTRAS are presented and comparisons between the measurement and HYSPLIT simulation are discussed.

\subsection{Time series of PMCP measurements}

Figure 6a shows a time series of PMCP tracer concentrations (red bars) along with altitude (in black) for the flight on 21 November 2011. In total, 33 air samples were collected during five crossings at three different flight levels (170, 500 , and $1000 \mathrm{~m}$ ). The measured PMCP concentrations range from 9.36 to $301.33 \mathrm{fmol} \mathrm{mol}^{-1}$, largely exceeding the mean PMCP background concentration measured at the ground $\left(6.62 \mathrm{fmol} \mathrm{mol}^{-1}\right)$ for most samples. Three time periods of clearly elevated PMCP concentrations are observed for the first three plume crossings during 07:00-07:25, 07:45-08:05, and 08:25-08:45 UTC (about $5 \mathrm{~h}$ after the release), at altitudes of 170,170 , and $500 \mathrm{~m}$, respectively. This demonstrates that the Falcon successfully sampled the tracer plume during these periods.

During the first sampling period at $170 \mathrm{~m}$ from northeast (NE) to southwest (SW), three samples collected between 07:06 and 07:15 UTC showed enhanced tracer concentrations relative to background concentrations. The maximum detected PMCP concentration $\left(301.33 \mathrm{fmol} \mathrm{mol}^{-1}\right)$ at 07:07 UTC is about 45 times higher than the mean background at the ground. Along both sides of the maximum, the detected PMCP concentrations decrease, reaching values close to the background level. At around 07:10 UTC there is a $5 \mathrm{~min}$ sampling gap, due to a short period of malfunction of the sampling pump. During this time interval, two samples could not be taken. During the second sampling period (07:45-08:05 UTC), when the Falcon flew from northwest (NW) to southeast (SE), most samples were clearly higher than the background, with a maximum value of $203.39 \mathrm{fmol} \mathrm{mol}^{-1}$. The expansion of the tracer plume in NW-SE direction is found to be broader than along the perpendicular direction (NE-SW), and the concentration variation of PMCP are comparatively moderate. During the third sampling period at around 08:2508:45 UTC, when the Falcon flew along the NE-SW direction again but at $500 \mathrm{~m}$, the PMCP concentrations show a quasi-symmetrical distribution. Very likely the Falcon flew through a narrow region of the tracer plume or just touched the fringe of the tracer plume. During the last sampling period from 09:05 to 09:25 UTC, two of the samples have slightly higher concentrations than the background. The samples collected at $1000 \mathrm{~m}$ (09:45-10:00 UTC) have PMCP concentrations close to background values. Probably the Falcon flew above the tracer plume here.

For the tracer sampling flight on 22 November, about $25 \mathrm{~h}$ after the release, a total of 27 samples, all except one, were successfully analyzed. The corresponding time series of PMCP concentrations is shown in Fig. $6 \mathrm{~b}$ (purple bars). Most PMCP values detected (maximum concentration 

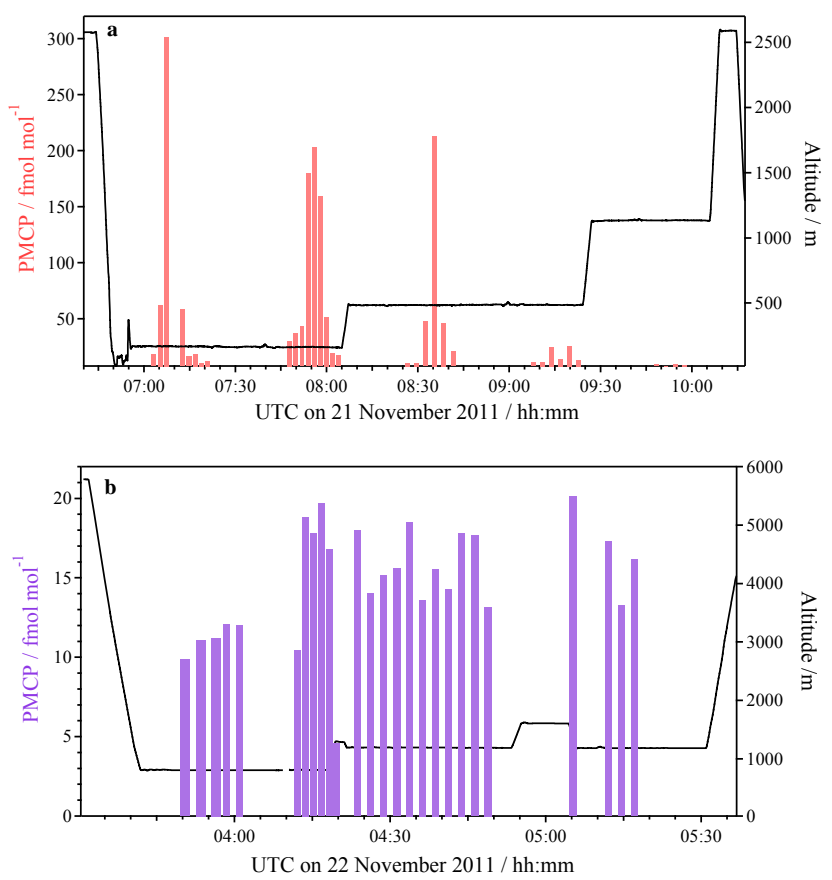

Figure 6. Time series of PMCP concentrations on 21 November (a) and 22 November 2011 (b). Each bar represents the averaged value during each sampling interval.

of $20.14 \mathrm{fmol} \mathrm{mol}^{-1}$ ) are higher than background. Unfortunately, the tracer plume was advected further south than forecast and partly over land. Therefore the lowest level of the Falcon possible was $1000 \mathrm{~m}$, and the sampling occurred only across the outer edge of the tracer plume.

\subsection{Comparison between the measurement and HYSPLIT simulations}

The comparisons between the PMCP measurements and the HYSPLIT simulations based on GDAS data for the flight on 21 November show in general a reasonably good agreement as illustrated in Fig. 7.

During the first sampling period (marked as " 1 " in Fig. 7) at around 07:10 UTC, the peak PMCP concentration simulated by HYSPLIT $\left(6190.74 \mathrm{fmol} \mathrm{mol}^{-1}\right)$ is much higher than the maximum PMCP concentrations observed (301.33 $\left.\mathrm{fmol} \mathrm{mol}^{-1}\right)$ (07:06-07:07 UTC); however, the HYSPLIT tracer maximum is calculated for the period where two samples could not be taken due to the short pump failure. The average PMCP concentration (279.31 fmol mol ${ }^{-1}$ ) calculated with HYSPLIT for the period 07:06-07:07 UTC is similar to the measurements.

During SHIVA, the University of Frankfurt operated also an in situ gas chromatograph, GHOST (Gas cHromatograph for the Observation of Stratospheric Tracers - coupled with a mass spectrometer), onboard the Falcon for measurements of halogen compounds (Bujok et al., 2001; Sala et al., 2014). GHOST was not prepared or calibrated to measure PFCs;

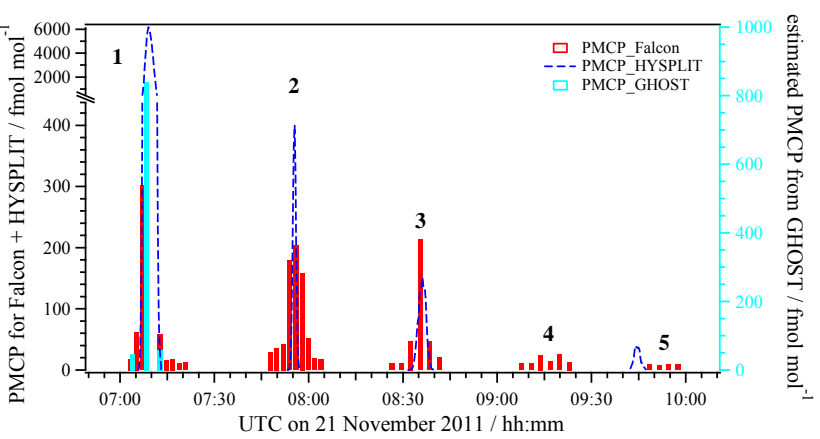

Figure 7. Time series of measured PMCP concentrations (red bars) on 21 November and HYSPLIT simulations using analyzed meteorological fields (blue dashed lines). Bluish-green bars represent the PMCP concentrations estimated from the signals of the GHOST instrument.

however it detected signals of PMCP during the tracer plume sampling.

Interestingly, during the sampling period 07:0007:15 UTC, three high signals of the PMCP tracer were detected by GHOST, one being extraordinarily high. One of the GHOST signals corresponds well in time with one of the PERTRAS samples during the period 07:12-07:13 UTC (the third bluish-green bar, Fig. 7). Based on the ratios of both signals to the calibration gas used for GHOST, the PMCP concentrations of the two other GHOST signals can be estimated collected from 07:03 to 07:04 UTC, between the first and the second sample of ATS, and from 07:07 to 07:08 UTC, starting just after the sample from ATS being finished at around 07:07 UTC. The GHOST estimates for the PMCP concentrations amount to 46.8 and $840.6 \mathrm{fmol} \mathrm{mol}^{-1}$, respectively, and are also shown in Fig. 7 as bluish-green bars (the first and the second one). Overall the PMCP measurements and the HYSPLIT simulations indicate that the Falcon was traversing the center of the tracer plume during the first sampling period.

For further comparisons of the PMCP measurements and HYSPLIT simulations, time snapshots of the tracer plume for each $10 \mathrm{~min}$ time interval for the sampling flight on 21 and 22 November are shown in Figs. 8 and 9. Here, the horizontal model layers are depicted which match best with the Falcon flight altitude during each 10 min time window from $t-5 \mathrm{~min}$ to $t+5 \mathrm{~min}$ for the corresponding samples. For those cases where the flight altitude varied by more than $100 \mathrm{~m}$ during the corresponding time window, the contours show, at each horizontal grid point, the highest volume mixing ratio (VMR) of any vertical model layer which the aircraft crossed. Those height ranges are indicated in the headings of the plots.

As shown in panels a and $\mathrm{b}$ of Fig. 8, which correspond to the sampling period of "1" in Fig. 7, the flight track almost passed through the center of the tracer plume as planned. In panel $b$, the samples collected at 07:07 UTC (yellow oval) 


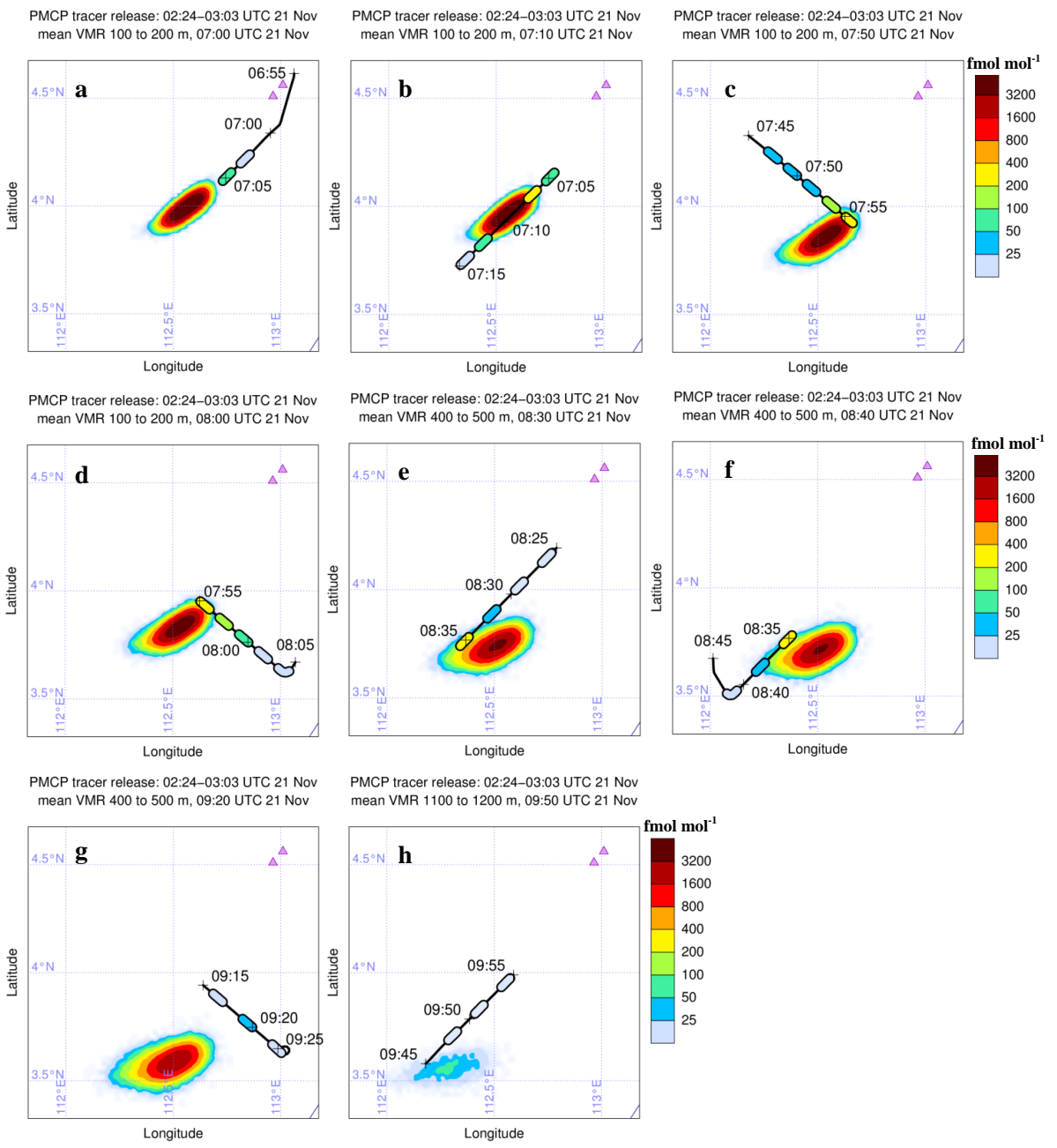

Figure 8. Time snapshots of the simulated tracer plume with HYSPLIT using analyzed meteorological fields (big plume) on 21 November, and the corresponding sampling tracks (black line). (a and b) The plume at $t=07: 00$ and 07:10 UTC, (c and d) the plume at $t=07: 50$ and 08:00 UTC, (e and f) the plume at $t=08: 30$ and 08:40 UTC, (g) the plume at $t=09: 20 \mathrm{UTC}$, and (h) the plume at $t=09: 50 \mathrm{UTC}$. The volume mixing ratio (VMR) is calculated as mean value within vertical layers of $100 \mathrm{~m}$ thickness, for (a-d) $100-200 \mathrm{~m}$, for $(\mathbf{e}-\mathbf{g}) 400-500 \mathrm{~m}$, and for (h) 1100-1200 m. Small colored ovals represent the samples collected along the flight track (same color scale as used for the HYSPLIT data). Two purple triangles indicate the positions of the start and the end of the tracer release.

and 07:12 UTC (green oval), with PMCP concentrations of 301.33 and $58.54 \mathrm{fmol} \mathrm{mol}^{-1}$, respectively, are quantitatively similar to the simulation results. However, one sample (another green oval in Fig. 8a and b) with a PMCP concentration of $62.58 \mathrm{fmol} \mathrm{mol}^{-1}$, very well above background values, was collected out of the main forecasted plume. This indicates that the simulation is underestimating the size of the plume in NE-SW direction at least by $10 \mathrm{~km}$. However, this difference can be regarded as reasonable since the model cannot reproduce such small variations in the measured tracer concentrations because it is below the resolution of the meteorological input data (Stohl et al., 1998).

For the other two sampling periods during 07:4508:05 UTC (Fig. 7, case 2) and 08:25-08:45 UTC (Fig. 7, case 3), the simulated PMCP concentrations are similar in magnitude to the measurements. These samples were mainly collected in the boundary region of the plume. As can be seen from Fig. 8c, during 07:45-08:05 UTC, two samples, illustrated as light-green and yellow ovals, with PMCP concentrations of 179.66 and $203.39 \mathrm{fmol} \mathrm{mol}^{-1}$, respectively, show reasonable agreement with the model but are located in the boundary of the plume in the northeastern direction. The plume was transported a little bit further to the south compared to the forecast used for flight planning. Two other samples illustrated as light-green $\left(159.36 \mathrm{fmol} \mathrm{mol}^{-1}\right)$ and green ovals $\left(51.96 \mathrm{fmol} \mathrm{mol}^{-1}\right)$ (Fig. 8d) are located outside of the simulated plume, which indicates that the plume in this area probably dispersed more (at least $12 \mathrm{~km}$ ) in the southeastern direction than simulated by the model. From the reanalysis for the time period 08:30-08:40 UTC (Fig. 8e and f), the 

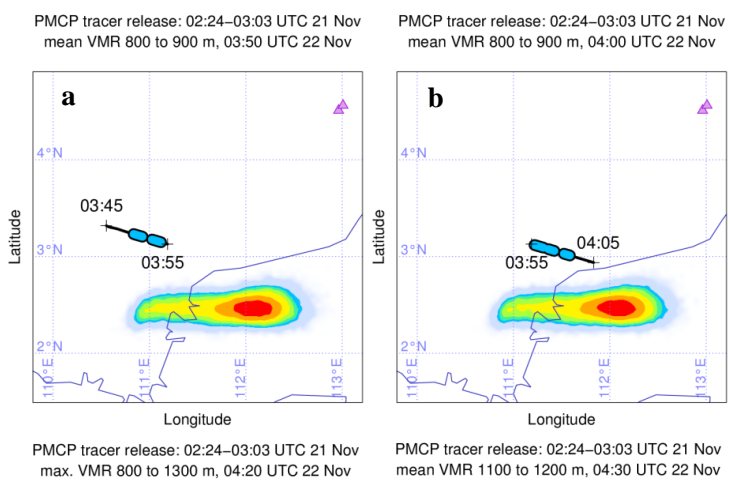
PMCP tracer release: 02:24-03:03 UTC 21 Nov
mean VMR 800 to $900 \mathrm{~m}, 04: 10$ UTC 22 Nov mean VMR 800 to $900 \mathrm{~m}, 04: 00$ UTC 22 Nov
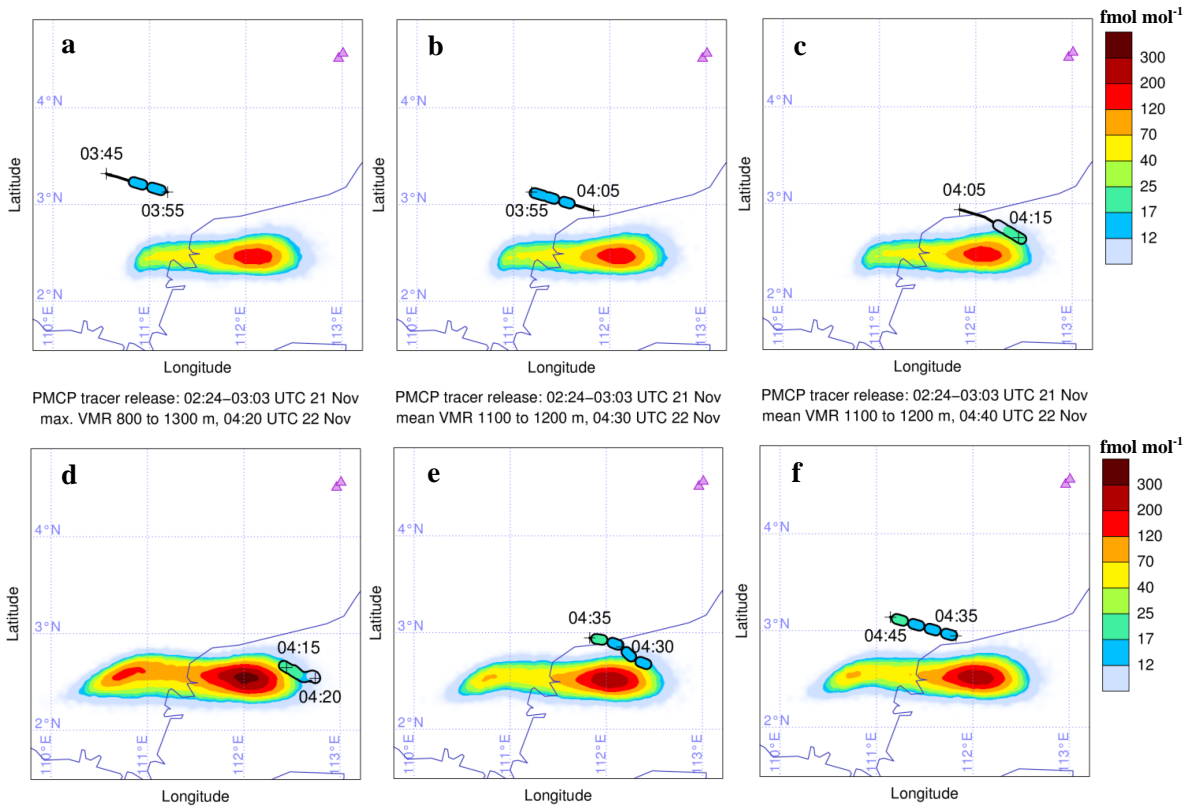

PMCP tracer release: 02:24-03:03 UTC 21 Nov mean VMR 1100 to $1200 \mathrm{~m}, 04: 30$ UTC 22 Nov

mean VMR 1100 to 1200 02:03:03 UTC 21 Nov

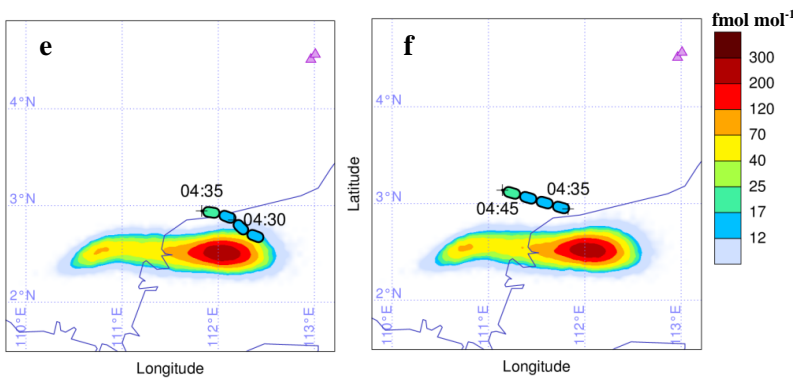

Figure 9. Time snapshots of the simulated tracer plume with HYSPLIT using analyzed meteorological fields (big plume) on 22 November, and the corresponding sampling tracks (black line). (a-f) The plume at $t=03: 50,04: 00,04: 10,04: 20,04: 30$, and 04:40 UTC, respectively. VMR is calculated as mean value within vertical layers from 800 to $900 \mathrm{~m}$ (a-c) and 1100 to $1200 \mathrm{~m}$ (e and f). Panel (d) picks, at any location, the maximum out of five vertical layers between 800 and $1300 \mathrm{~m}$, because the flight altitude changed during this section. Small colored ovals represent the samples collected along the flight track (same color scale as used for the HYSPLIT data). Two purple triangles indicate the positions of the start and the end of the tracer release.

flight track seems to have touched the southwestern edge of the plume as speculated in Sect. 4.1. This implies that the tracer plume in reality was advected further to the southeast. Although the Falcon mostly did not fly through the plume center as planned, the results from the measurements (Fig. 7) coincide with the HYSPLIT simulations quite well.

The results of samples collected during the fourth and fifth sampling period (marked as "4" and " 5 " in Fig. 7) at around 09:15 and 09:55 UTC are not captured by the simulations. This suggests that the tracer plume moved away already from the sampling area, which can be seen more clearly in Fig. $8 \mathrm{~g}$ and $h$.

The plume simulation at $5 \mathrm{~h}$ after the release underestimates the along-wind size by some $20 \%$ (Fig. $8 \mathrm{~b}$ ) and the cross-wind size by a factor of roughly 1.5-2 (Fig. 8c/d) compared with the size inferred from the locations of the samples taken with the ATS. This is consistent with an overestimation of maximum concentrations in the dispersion simulation compared with the results from PERTRAS for the crossings at 07:10 and 07:55 UTC, implying an underestimation of dispersion and mixing by HYSPLIT. However, at this time the size of the plume is significantly smaller than the grid spacing of the driving wind field data, which might result in an underestimation of the stretching and folding of the plume by local sub-grid scale wind variations. In addition, an underestimation of the turbulent velocity components for that spe- cific meteorological condition cannot be ruled out. As a consequence, preparation and execution of future tracer release experiments would strongly benefit from the use of higherresolution meteorological forecast data, if available.

For the sampling flight on 22 November, if the analysis of HYSPLIT is correct, the Falcon sampled north of the main plume, barely touching the northeastern edge from 04:10 to 04:30 (shown in Fig. 9). According to the HYSPLIT forecast, which was used for the flight planning, the tracer plume should have been located further north. Another difficulty for the flight plan was that the plume was located partly over land and a minimum possible flight altitude of the Falcon was required to be $1000 \mathrm{~m}$. The latest updated HYSPLIT forecasts for the flight on 22 November after the takeoff of the Falcon already showed that the tracer plume center was moving faster and more to the south; however, the flight track of the Falcon could not be changed due to telecommunication loss with the Falcon because of the low flight altitude. Therefore the Falcon collected samples according to the flight plan made before takeoff. The results from the measurement basically confirm the post-flight simulation of HYSPLIT using analyzed meteorological data. 


\section{Summary and conclusion}

We have presented a newly developed perfluorocarbon tracer system, PERTRAS, including a tracer release unit, an adsorption tube sampler, and an analyzing system (TD-GC-NICIMS). The tracer RU is highly portable, can be automatically operated, and is suitable for the deployment on different platforms (ground station, ship, and aircraft) depending on the objective of the tracer experiment, although it was designed for the application aboard aircraft. The tracer release rate can be adjusted between 0.1 and $500 \mathrm{~mL} \mathrm{~min}^{-1}$ with an uncertainty of $2 \%$ using a HPLC pump, and up to a total of $30 \mathrm{~kg}$ and three different PFCs can be released. Up to 64 tracer samples can be taken during a flight with the tracer sampler ATS. The sampling procedure can be programmed including sequences with standby/waiting and sampling modes. All sample tubes are analyzed with a high selective and sensitive TD-GC-NICI-MS system in the laboratory with a limit of detection of $1.2 \mathrm{fmol} \mathrm{mol}^{-1}$.

During the SHIVA field campaign in November 2011, the new PERTRAS system was applied for the first time. The tracer release was conducted on the deck of RV Sonne, and $8.8 \mathrm{~kg}$ PMCP was released during a period of $39 \mathrm{~min}(02: 24$ to 03:03 UTC). The tracer was sampled by the DLR research aircraft Falcon using the ATS during two flights on 21 and 22 November, approximately 5 and $25 \mathrm{~h}$ after the release, respectively. In total, 63 samples including four blanks were collected, with a time resolution of $1 \mathrm{~min}$, and analyzed after the campaign in the DLR laboratory using a TD-GC-NICIMS system. The result of all blank samples shows that no contamination occurred during the transport of the sampling tubes to the campaign site and back, as well as during sampling and analysis.

During the sampling flight on 21 November the tracer plume was intercepted successfully several times and a reasonable agreement was found between the tracer measurements and post-flight HYSPLIT simulations using analyzed meteorological fields. It could be demonstrated that the entire PERTRAS system worked reliably. The plume simulated by HYSPLIT is somewhat smaller than the one inferred from the measurement for the first three sampling periods for the 21 November flight, implying a slight underestimation of dispersion and mixing by HYSPLIT.

The tracer plume was largely missed during the flight on 22 November for several reasons. Firstly, there was a restriction of the minimum flight altitude to $1000 \mathrm{~m}$ since the tracer plume was advected partly over land. Secondly, a needed adjustment of the flight pattern after the Falcon takeoff based on the latest HYSPLIT forecasts could not be transmitted to the Falcon crew due to a loss of telecommunication because of the low flight altitude. These problems should not occur for tracer experiments at higher altitudes.

The tracer experiment during SHIVA demonstrated the capability of the new tracer system PERTRAS to unambiguously identify and trace an air mass tagged with a PFC. This proof-of-concept study provides the practical basis for the application of the PFC tracer system in future aircraft experiments in the FT and UT-LS to quantify small-scale diffusion parameters and synoptic-scale flow distortion in this altitude region. Furthermore, the release of two different PFC tracers will be helpful to understand the mixing between distinct air masses, in particular near the tropopause. Moreover, the tagging of air masses with PFC tracers can significantly support Lagrangian experiments to study chemical process and aerosol transformations. In addition, investigations of transport and multiphase processes in convective clouds can be facilitated by tagging the air with a PFC tracer in the inflow region and sampling the tracer in the outflow region.

After the successful deployment of PERTRAS during the SHIVA field campaign, further tracer experiments are planned to study transport and transformation processes in deep convection in the tropics and in large scale pollution plumes of megacities in Asia. Recently, the PERTRAS system has been applied successfully during the campaign TNAWDEX-Falcon in a warm conveyor belt over Europe. Analysis of this data is ongoing, and results will be presented in a forthcoming paper.

Acknowledgements. This work was funded by the Deutsche Forschungsgemeinschaft (DFG) under Priority Program HALO SPP 1244 (SCHL 1857/1-2) and by the EU project SHIVA (EU-226224). We especially thank Michael Lichtenstern (DLR) for his excellent work of constructing PERTRAS instrumentation. We thank Russel N. Dietz and Thomas B. Watson of the Brookhaven National Laboratory for very helpful advice in all aspects of the PFC technology. We also thank Dominik Schäuble and Tina Jurkat (DLR) for the tracer release from RV Sonne and Klaus Pfeilsticker and Marcel Dorf (University of Heidelberg) for coordinating the SHIVA campaign. Stephan Sala and Andreas Engel (Goethe University Frankfurt) are acknowledged for providing the GHOST data. Thanks are also due to Damien Martin (University of Bristol) for providing the gas standard. We acknowledge the support of the pilots and staff of the DLR Flight Department and the help of Anke Roiger, Anja Reiter, and Heinfried Aufmhoff (DLR) during the campaign. We are thankful to the NOAA Air Resources Laboratory for providing the HYSPLIT model.

The service charges for this open access publication have been covered by a Research Centre of the Helmholtz Association.

Edited by: W. T. Sturges

\section{References}

Ambrosetti, P., Anfossi, D., Cieslik, S., Graziani, G., Lamprecht, R., Marzorati, A., Nodop, K., Sandroni, S., Stingele, A., and Zimmermann, H.; Mesoscale transport of atmospheric trace constituents across the central Alps: Transalp tracer experiments, Atmos. Environ., 32, 1257-1272, 1998. 
Aragón, M., Borrull, F., and Marcé, R. M.: Thermal desorption-gas chromatography-mass spectrometry method to determine phthalate and organophosphate esters from air samples, J. Chromatogr. A, 1301, 76-82, 2013.

Aschmann, J., Sinnhuber, B.-M., Atlas, E. L., and Schauffler, S. M.: Modeling the transport of very short-lived substances into the tropical upper troposphere and lower stratosphere, Atmos. Chem. Phys., 9, 9237-9247, doi:10.5194/acp-9-9237-2009, 2009.

Bates, T. S., Huebert, B. J., Gras, J. L., Griffiths, F. B., and Durkee, P. A.: International Global Atmospheric Chemistry (IGAC) Project's First Aerosol Characterization Experiment (ACE1): Overview, J. Geophy. Res., 103, 16297-16318, doi:10.1029/97JD03741, 1998.

Begley, P., Foulger, B., and Simmonds, P.: Femtogram detection of perfluorocarbon tracers using capillary gas chromatographyelectron-capture negative ion chemical ionization mass spectrometry, J. Chromatogr., 445, 119-128, 1998.

Bujok, Q., Tan, V., Klein, E., Nopper, R., Bauer, R., Engel, A., Gerhards, M., Afchine, A., Mckenna, D. S., Schmidt, U., Wiedhold, F. G., and Fischer, H.: GHOST - A novel airborne gas chromatograph for in situ measurements of long-lived tracers in the lower stratosphere: method and applications, J. Atmos. Chem., 39, 3764, 2001.

Clarke, A. D., Uehara, T., and Porter, J. N.: Lagrangian evolution of an aerosol column during the Atlantic Stratocumulus Transition Experiment, J. Geophy. Res., 101, 4351-4362, doi:10.1029/95JD02612, 1996.

Cooke, K. M., Simmonds, P. G., Nickless, G., and Makepeace, A. P. W.: Use of capillary gas chromatography with negative ion-chemical ionization mass spectrometry for the determination of perfluorocarbon tracers in the atmosphere, Anal. Chem., 73, 4295-4300, 2001.

DeBortoli, M. and Pecchio, E.: Sensitive determination of perfluorocarbon tracers in air by intermediate trapping and GC-ECD Analysis, J. High Res. Chromotog., 8, 422-425, 1985.

Dietz, R. N.: Perfluorocarbon tracer technology, Regional and Long-Range Transport of Air Pollution, edited by: Sandroni, S., Elsevier, Amsterdam, 215-247, 1986.

Draxler, R. R.: Metropolitan Tracer Experiment (METREX), NOAA Tech. Memo. ERL, ARL-140, 1985.

Draxler, R. R. and Heffter, J. L.: Across North America Tracer Experiment (ANATEX), Volume 1: description, ground-level sampling at primary sites, NOAA Tech. Memo., ERL, ARL-167, 1989.

Draxler, R. R. and Hess, G. D.: Description of the HYSPLIT_4 modeling system, NOAA Tech. Memo. ERL, ARL-224. 1997.

Draxler, R. R. and Hess, G. D.: An overview of the HYSPLIT_4 modeling system of trajectories, dispersion and deposition, Aust. Meteorol. Mag., 47, 295-308, 1998.

Draxler, R. R., Dietz, R. N., Lagomarsino, R. J., and Start, G.: Across North America Tracer Experiment (ANATEX): sampling and analysis, Atmos. Environ., 25A, 2815-2836, 1991.

Fehsenfeld, F. C., Ancellet, G., Bates, T. S., Goldstein, A. H., Hardesty, R. M., Honrath, R., Law, K. S., Lewis, A. C., Leaitch, R., McKeen, S., Meagher, J., Parrish, D. D., Pszenny, A. A. P., Russel, P. B., Schlager, H., Seinfeld, J., Talbot, R., and Zbinden, R.: International Consortium for Atmospheric Research on Transport and Transformation (ICARTT): North America to Europe-
Overview of the 2004 summer field study, J. Geophy. Res., 111, D23S01, doi:10.1029/2006JD007829, 2006.

Ferber, G. J., Telegadas, K., Heffter J. L., Dickson, C. R., Dietz, R. N., and Philip, W. K.: Demonstration of a long-range atmospheric tracer system using perfluorocarbons, Final Report, EPA600, 1981.

Ferber, G. J., Heffter, J. L., Draxler, R. R., Lagomarsion, R. J., Thomas, F. L., Dietz, R. N., and Benkovitz, C. M.: CrossAppalachian Tracer Experiment (CAPTEX 83), Final Report, NOAA Tech. Memo., ERL, ARL-142, 1986.

Galdiga, C. U. and Greibrokk, T.: Ultra trace detection of perfluorocarbon tracers in reservoir gases by adsorption/thermal desorption in combination with NICI-GC/MS, Fresen, J. Anal. Chem., 367, 43-50, 2000.

Green, M., Kuhns H., Pitchford, M., Dietz, R., Ashbaugh, L., and Watson, T.: Application of the tracer-aerosol gradient interpretive technique (TAGIT) to sulfur attribution for the Big Bend Regional Aerosol and Visibility Observational (BRAVO) study, J. Air Waste Manage., 53, 586-595, 2003.

Green, M. C.: The project MOHAVE tracer study: study design, data quality, and overview of results, Atmos. Environ., 33, 19551968, 1999.

Huebert, B. J. and Lenschow, D. H.: What have Lagrangian experiments accomplished?, IGACtivity Newsletter, 17, 4-8, 1999.

Johnson, D. W., Osborne, S., Wood, R., Suhre, K., Johnson, R., Businger, S., Quinn, P. K., Wiedensohler, A., Durkee, P. A., Russell, L. M., Andree, M. O., O’Dowd, C., Noone, K. J., Bandy, B., Rudolph, J., and Rapsomanikis, S.: An overview of the Lagrangian experiments undertaken during the North Atlantic regional Aerosol Characterization Experiment (ACE-2), Tellus, 52B, 290-320, 2000.

Kim, H. K., Yea, S. K., Ro, C. U., Lee, C. B., Jang, M., Lee, G., Yoo, E., and Han, J. S.: Determination of atmospheric perfluorocarbon background concentrations of fl/L Range at the western Coastal Area of Korea, B. Korean Chem. Soc., 23, 301-308, 2002.

Lagomarsino, R. J.: An improved gas chromatographic method for the determination of perfluorocarbon tracers in the atmosphere, J. Chromatogr. Sci., 34, 405-412, 1996.

Lin, J. C., Gerbig, C., Wofsy, S. C., Andrews, A. E., Daube, B. C., Grainger, C. A., Stephens, B. B., Bakwin, P. S., and Hollinger, D. Y.: Measuring fluxes of trace gases at regional scales by Lagrangian observations: Application to the $\mathrm{CO}_{2}$ Budget and Rectification Airborne (COBRA) study, J. Geophy. Res., 109, D15304, doi:10.1029/2004JD004754, 2004.

Methven, J., Arnold, S. R., Stohl, A., Evans, M. J., Avery, M., Law, K., Lewis, A. C., Monks, P. S., Parrish, D., Reeves, C., Schlager, H., Atlas, E., Blake, D., Coe, H., Cohen, R. C., Crosier, J., Flocke, F., Holloway, J. S., Hopkins, J. R., Hübler, G., McQuaid, J., Purvis, R., Rappenglück, B., Ryerson, T. B., Sachse, G. W., Singh, H., Watson, N., Whalley, L. K., and Williams, P.: Establishing Lagrangian connections between observations within air masses crossing the Atlantic during the ICARTT experiment, J. Geophy. Res., 111, D23S62, doi:10.1029/2006JD007540, 2006.

Nodop, K., Connolly, R., and Girardi, F.: The field campaigns of the European Tracer Experiment (ETEX): Overview and results, Atmos. Environ., 32, 4095-4108, 1998.

Piringer, M., Baumann, K., Rötzer, H., Riesing, J., and Nodop, K.: Results on perfluorocarbon background concentrations in Austria, Atmos. Environ., 31, 515-527, 1997. 
Ren, Y., Schlager, H., and Martin, D.: The application of TD/GC/NICI-MS with an $\mathrm{Al}_{2} \mathrm{O}_{3}$-PLOT-S column for the determination of perfluoroalkylcycloalkanes in the atmosphere, Chromatogr., 77, 309-316, 2014.

Sala, S., Bönisch, H., Keber, T., Oram, D. E., Mills, G., and Engel, A.: Deriving an atmospheric budget of total organic bromine using airborne in situ measurements from the western Pacific area during SHIVA, Atmos. Chem. Phys., 14, 6903-6923, doi:10.5194/acp-14-6903-2014, 2014.

Simmonds, P. G., Greally, B. R., Olivier, S., Nickless, G., Cooke, K. M., and Dietz, R. N.: The background atmospheric concentrations of cyclic perfluorocarbon tracers determined by negative ion-chemical ionization mass spectrometry, Atmos. Environ., 36, 2147-2156, 2002.

Straume, A. G., Dietz, R. N., Koffì, E. N., and Nodop, K.: Perfluorocarbon background concentrations in Europe, Atmos. Environ., 32, 4109-4122, 1998.

Stohl, A., Hittenberger, M., and Wotawa, G.: Validation of the Lagrangian particle dispersion model FLEXPART against largescale tracer experiment data, Atmos. Environ., 32, 4245-4264, 1998.
Tegtmeier, S., Krüger, K., Quack, B., Atlas, E. L., Pisso, I., Stohl, A., and Yang, X.: Emission and transport of bromocarbons: from the West Pacific ocean into the stratosphere, Atmos. Chem Phys., 12, 10633-10648, doi:10.5194/acp-12-10633-2012, 2012.

Tegtmeier, S., Krüger, K., Quack, B., Atlas, E., Blake, D. R., Boenisch, H., Engel, A., Hepach, H., Hossaini, R., Navarro, M. A., Raimund, S., Sala, S., Shi, Q., and Ziska, F.: The contribution of oceanic methyl iodide to stratospheric iodine, Atmos. Chem. Phys., 13, 11869-11886, doi:10.5194/acp-13-11869-2013, 2013.

Watson, T. B., Wilke, R., Dietz, R. N., Heiser, J., and Kalb, P.: The atmospheric background of perfluorocarbon compounds used as tracers, Environ. Sci. Technol., 41, 6909-6913, 2007.

Yang, Y. Q., He, J. B., Ye, S. Y., and Yang, T. Z.: Penetration capacity of trace perfluorodimethylcyclobutane through Carboxen 569 Adsorbent, Atomic Energy Science Technology, 39, 404 408, 2005. 